\title{
The Modeling and Simulation of Heat Transfer in Flat Platesolar Collector Using Software Engineering Equation Solver
}

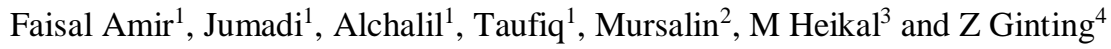 \\ \{mursalin@unimal.ac.id\} \\ ${ }^{1}$ Department of Mechanical Engineering Education, Universitas Malikussaleh, Aceh, Indonesia \\ ${ }^{2}$ Department of Mathematics Education, Universitas Malikussaleh, Aceh, Indonesia \\ ${ }^{3}$ Department of Management, Universitas Malikussaleh, Aceh, Indonesia \\ ${ }^{4}$ Department of Chemical Engineering, Universitas Malikussaleh, Aceh, Indonesia
}

\begin{abstract}
Solar collector is a device that serves to collect the incoming solar energy and convert it into energy which in turn forwarded to the working fluid. A great systemof solar collector is a solar collector which has high efficiency, this means, most of heat energy that absorbed the collector can be used to water heater that flows inside and a small portion of heat energy is lost to the environment. In this study, the model of solar collectors has been modeled and heat transfer process to the solar collector solved by using software Engineering Equation Solver (EES). Iteration method is used to determine surface temperature in order to get useful heat energy on the collector. The solar collector simulated is measuring $1 \mathrm{~m} \times 2 \mathrm{~m} \times 0,06 \mathrm{~m}$, assumed absorber plate is aluminum and zinc plate size $0.4 \mathrm{~mm}$ and $0,6 \mathrm{~mm}$. The simulation results obtained fluid out temperature by using aluminum as the absorber is much higher than using zinc plate as the absorber plate. The fluid out temperature using aluminum plates as an absorber measuring $0.4 \mathrm{~mm}$ is higher than the plate size of $0.6 \mathrm{~mm}$. The temperature of out fluid by using a copper pipe is larger than using a metal pipe for flat plate collectors for copper pipe that has higher thermal conductivity than the steel pipe. The simulation results are compared with the results of testing and the fluid out temperature of the test results is obtained less than the simulation results using the collector pipes and absorber plate of the same.
\end{abstract}

Keywords: Flat Plate Solarcollectors, Solar Energy, Modelingand Simulation, Heattransfer.

\section{Introduction}

A good solar collector is a highly efficient solar collector, in other words, most of the heat that affects the solar collector can be used to heat the fluid that flows in it and reduce significant of heat lost to the environment [1]. Heat lost that released to the environment as it is reflected in returned by the cover and absorbent plate and partly lost to the environment through the bottom and side portions of the solar collector. Since the side portion is relatively small compared to the bottom and top part, the heat loss through the side is negligible. A good solar collector is determined by the geometry of the model and the type of materials [2]. 
The main components of solar collectors are consists of the cover section, air gap, and absorber, working fluid, and insulation layers. One of the most important parts of solar collectors is the absorber part [3].

Solar water heating systems have reached technical maturity and are used in many countries. After the first oil crisis in1973, the strategies used by industrialised and developing countries to reduce their oil dependence have been numerous. A diversification of energy import, a structural change of the large domestic product (industrial development of activities using a low energy expenditure) or an icrease of the national supply have been the essential measures taken by the countries with various degree of importance [4].

Nowadays, as the development of computer utilization in analyzing a wide range of problems, including in thermal science-modeling and simulation are commonly used among others methods.

Modeling is a method of mathematical equations that aim to explain the physical phenomena of the model of the study. In solar water heater collectors, modeling can be interpreted as the implementation of mathematical equations that aims to get the phenomenon of heat transfer that occurs in the collector [5].

In this research, modeling and simulation of heat transfer will be performed as numerical analyses by using a numerous of equations. The equations will be simulated by using software Engineering Equation Solver (EES). Also, the physical properties are available completely provided by the software.

In this research, the model will be developed by compiling a number of equations in order to perform the simulation. Many of the models have been proposed but were highly dependent on the location where modeling and testing were performed.

The purpose of this research is to develop numerical equations of heat transfer phenomenon and simulate it as mathematically on flat plate of solar collector. Furthermore the results will becompared with the experiment results. The results are expected to provide an overview of the calculation of heat transfer for water heaters in flat plate solar collectors and can develop science and technology in accordance with the development of the era.

\section{Literature Review}

\subsection{Modelling and simulation}

Modeling is the implementation of numerous numbers of mathematical equations that aim to explain the physical phenomena of the model. In solar water heater collectors, modeling can be interpreted as the use of mathematical equations that aims to get the phenomenon of heat transfer that occurs in the collector [6].

Making a model of solar water heater for the process of making food and comparing with measurements on the real conditions of the object. The development of a mathematical model is based on a numerical method called the Elementary Balance Method on each collector element represented by the node and the relevant energy balance equation for each collector element [7]. 


\subsection{Heat energy utilization from the collector}

The useful heat energy of the solar collector can be determined in three different ways. Based on the outer balance of the absorber, the useful heat energy of the collector using the following equation:

$$
\dot{Q}_{u}=A_{a}\left[(\tau \alpha)_{e f} G-U\left(t_{a b s}-t_{a}\right)\right]
$$

The heat energy that comes out based on absorber tabs temperature is not easy to know because with experimental measurement it is difficult to identify tabs.

The heat energy that comes out based on the average tm of fluid temperature is more easily known, as it corresponds to the experimental test results on the solar collector [8]. The average fluid temperature can be obtained easily from the measurement of inlet temperature and exit temperature.

The heat energy that comes out based on absorber tabs temperature is not easy to know because with experimental measurement it is difficult to identify tabs.

The heat energy coming out based on the average tm of fluid temperature is more easily known, as it corresponds to the experimental test results on the solar collector. The average fluid temperature can be obtained easily from the measurement of inlet temperature and exit temperature [9].

$$
t_{m}=\frac{t_{\text {in }}+t_{\text {out }}}{2}
$$

The heat energy coming out of the collector based on the average fluid temperature is determined by the efficiency factor F'.

$$
\dot{\mathrm{Q}}_{\mathrm{u}}=\mathrm{A}_{\mathrm{a}} \mathrm{F}^{\prime}\left[(\tau \alpha)_{\mathrm{ef}} \mathrm{G}-\mathrm{U}\left(\mathrm{t}_{\mathrm{m}}-\mathrm{t}_{\mathrm{a}}\right)\right]
$$

In the mathematical model of the solar energy system, to calculate the heat energy and the exit temperature of the collector is calculated according to the inlet temperature. The useful heat according to the inlet temperature can be given as in equation 3 .

In the mathematical model of the solar energy system, to calculate the heat energy and the exit temperature of the collector is calculated according to the inlet temperature [10]. The useful heat according to the inlet temperature can be given as in equation 4 .

$$
\dot{\mathrm{Q}}_{\mathrm{u}}=\mathrm{A}_{\mathrm{a}} \mathrm{F}_{\mathrm{R}}\left[(\tau \alpha)_{\mathrm{ef}} \mathrm{G}-\mathrm{U}\left(\mathrm{t}_{\mathrm{in}}-\mathrm{t}_{\mathrm{a}}\right)\right]
$$

To obtain the exit fluid temperature at the flat plate solar collector by means of equilibrium of the inner and outer energy as shown in equation 5.

$$
\mathrm{Q}=\mathrm{m} \cdot \mathrm{cp} \cdot \Delta \mathrm{T}=\dot{\mathrm{m}} \cdot \mathrm{cp} \cdot \Delta \mathrm{T}
$$

Then the fluid temperature out of the equation will be:

$$
\mathrm{T}_{\text {out }}=\mathrm{t}_{\text {in }}+\frac{\mathrm{Q}_{\mathrm{u}}}{\dot{\mathrm{m} c \mathrm{p}}}
$$




\section{Materials And Methods}

The process for solving the heat transfer equation modeling of a flat plate solar collector, by using thermal resistance as shown in Fig. 1, therefore computer programming is required in order to solve several variables and unknown equations [11].

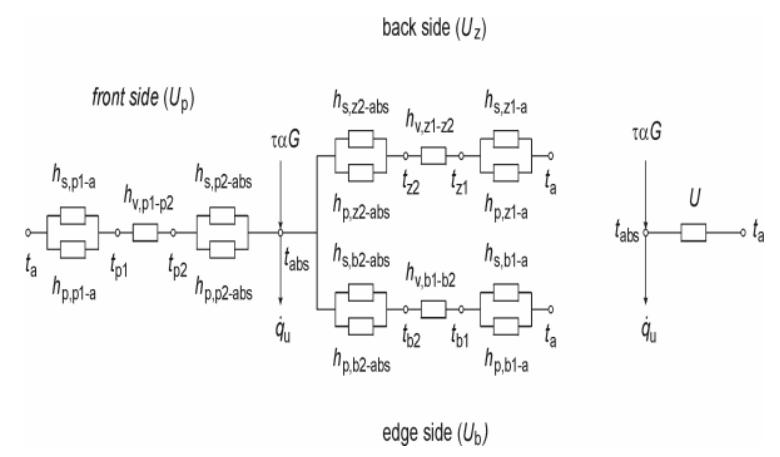

Figure 1. Thermal resistance of energy equilibrium in solar collector

\subsection{Collector dimension}

The geometry of plate solar collector as shown in Figure 2. The height of the La isassumed/considered to be the same as the length of the pipe. The width of Ha is divided by the number of pipe nr width of absorber fins given as $\mathrm{W}$ (the distance between two axes). The thickness of the dfr frame, the thickness of the front side air layer dp, the thickness of rear air layerdz and the thickness of the glassdgl with the total depth of the collector is given as B.
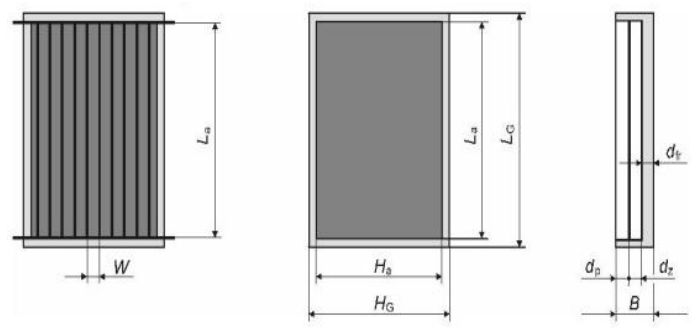

Figure 2. Dimension of solar collector

The specifications of each of the simulated components are:

1. The frame of the collector: made of aluminum material with thickness of 0.03 meters;

2. The length of the collector: $1 \mathrm{~m}$, collector width $2 \mathrm{~m}$ and the volume of collector area $2 \mathrm{~m}^{2}$;

3. There are two variations of flat absorber:

- The absorber plate used is aluminum material with thickness $0.4 \mathrm{~mm}$ and $0.6 \mathrm{~mm}$

- Zinc absorber plate with thickness $0.4 \mathrm{~mm}$ and $0.6 \mathrm{~mm}$.

4. Glass cover: clear glass with a thickness of $4 \mathrm{~mm}$

5. Collector absorber pipe: copper pipe with outside diameter $10 \mathrm{~mm}, 8 \mathrm{~mm}$ inner diameter. 


\section{Results And Discussion}

\subsection{Simulation results}

The following will show some results from simulations that have been executed based on the program that has been created with different input data and the flow rate used is $200 \mathrm{cc} / \mathrm{min}$, then the simulation result will be compared with the test result.

Case 1

Data input:

- Solar intensity is assumed under bright sky conditions, ambient temperatures, incoming fluid temperatures;

- Material absorber used is Aluminum with thickness $0.4 \mathrm{~mm}$ and $0.6 \mathrm{~mm}$;

- The pipe material used is copper;

- Data retrieval time from 08.00 am until $18.00 \mathrm{pm}$.

Case 2

Data input:

- Solar intensity is assumed under bright sky conditions, ambient temperatures, incoming fluid temperatures;

- Material absorbers used are zinc with thickness of $0.4 \mathrm{~mm}$ and $0.6 \mathrm{~mm}$;

- Pipe material used is iron;

- Data retrieval time from 8:00 am to $18: 00 \mathrm{pm}$.

The data obtained from the simulation and test results of flat plate solar water heaters, test results and simulations are discussed in graphical form. The graph of the intensity of solar radiation over time can be seen in Figure 3.

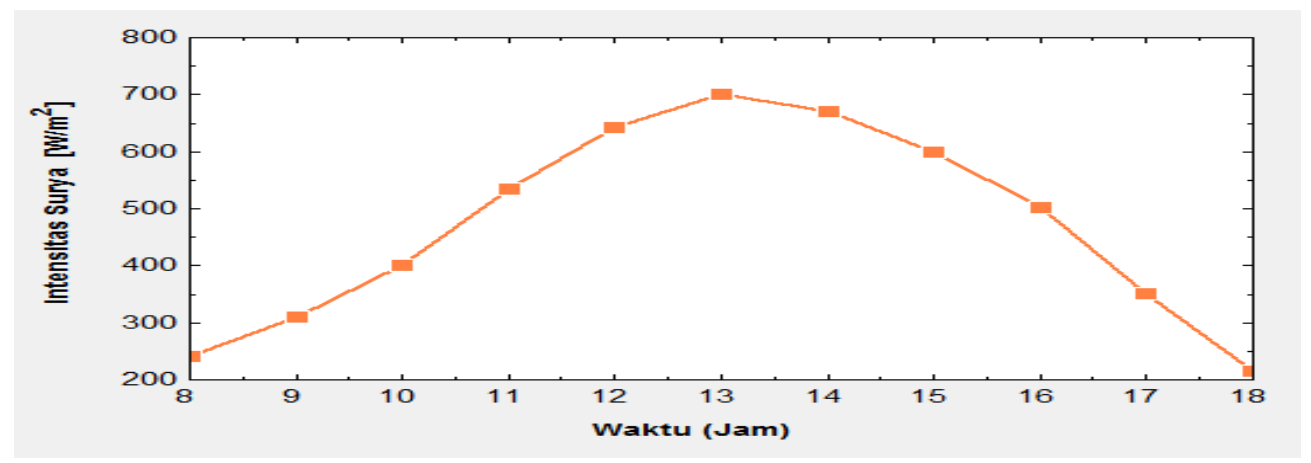

Figure 3. Graphsolar radiation intensity against time

At the beginning of the simulation of the absorber plate used was aluminum then replaced with zinc with the same thickness $(0.4 \mathrm{~mm})$, where the temperature of the inlet fluid (Tin), ambient temperature (Ta), the outlet fluid temperature of the simulated results by using the aluminum plate as Absorber (Tout: Abs of Aluminum) and the fluid temperature comes out from the simulation result using zinc as absorber plate (Tout; Abs of Zinc). 
The simulation results of media influence on temperature are shown in Fig 4 below.

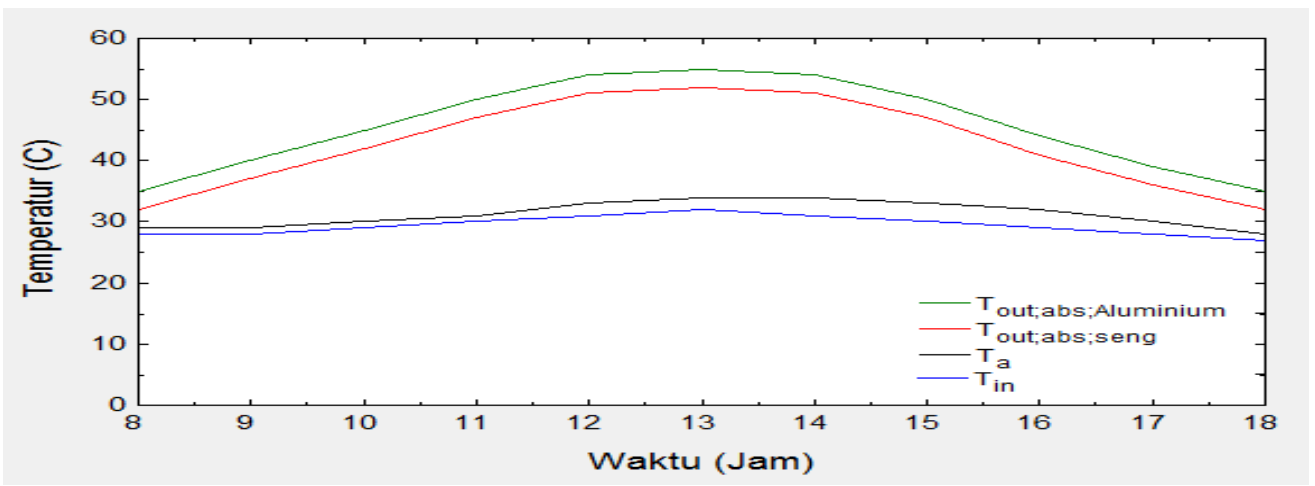

Figure 4. Graph temperature of out fluid based on the absorber plate

The next simulation is by varying the thickness of the absorber plate using aluminum with a thickness of 0.4 and $0.6 \mathrm{~mm}$. The collector pipe used is a copper pipe. The effect of thickness on the fluid out temperature can be explained in Figure 5.

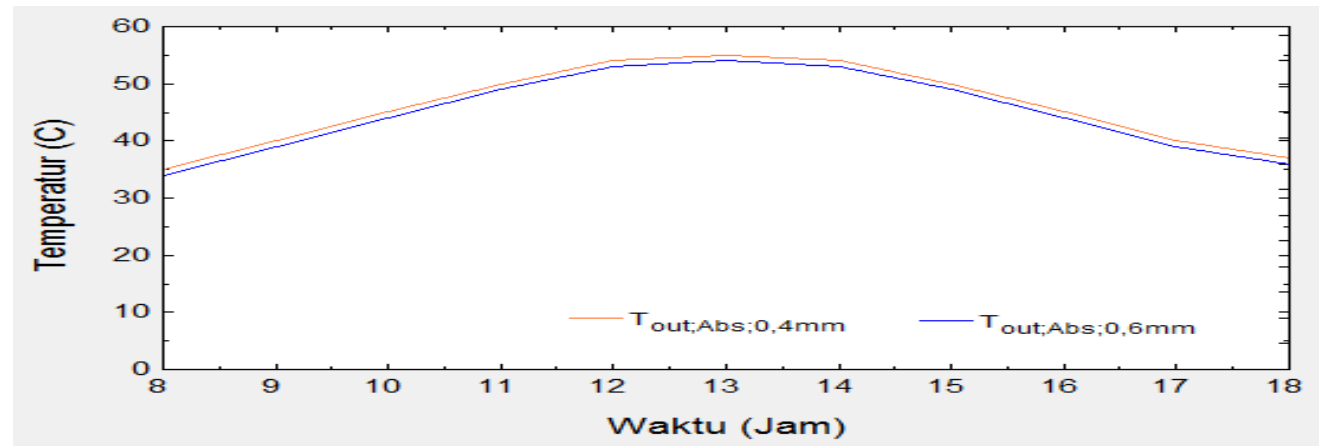

Figure 5. Graph temperature of out fluid based on the thickness of absorber plate

The next simulation varied the thickness of the absorber plate using the zinc with a thickness of $0.4 \mathrm{~mm}$ (Tout;Abs; 0,4) and $0.6 \mathrm{~mm}$ (Tout; Abs; 0,6) thickness. The effect of thickness on the fluid out temperature can be explained in Fig. 6. 


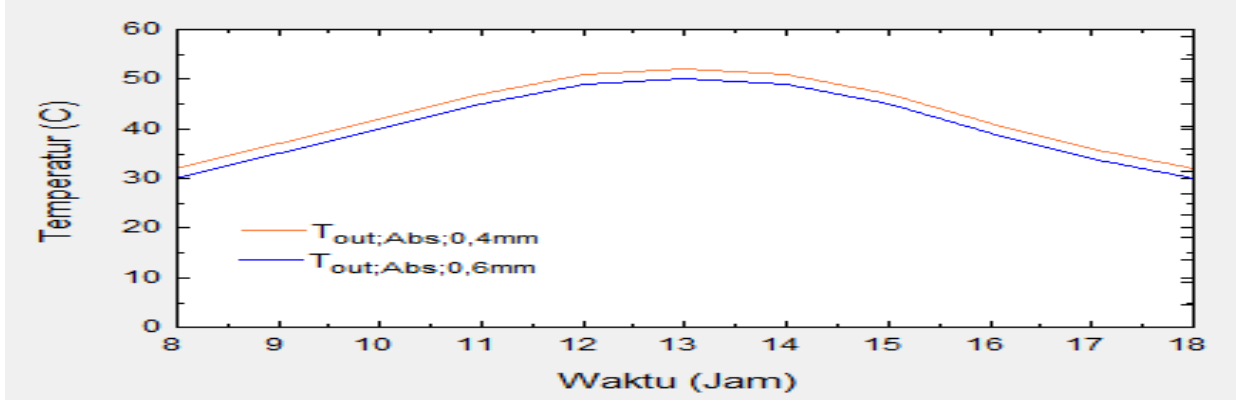

Figure 6. Graph temperature of out fluid based on the thickness of the absorber plate

The next simulation is done by varying the collector pipe using copper pipe and iron pipe with solar intensity, ambient temperature and ambient temperature equal. The effect of the collector pipe material on the fluid out temperature can be explained in Fig 7.

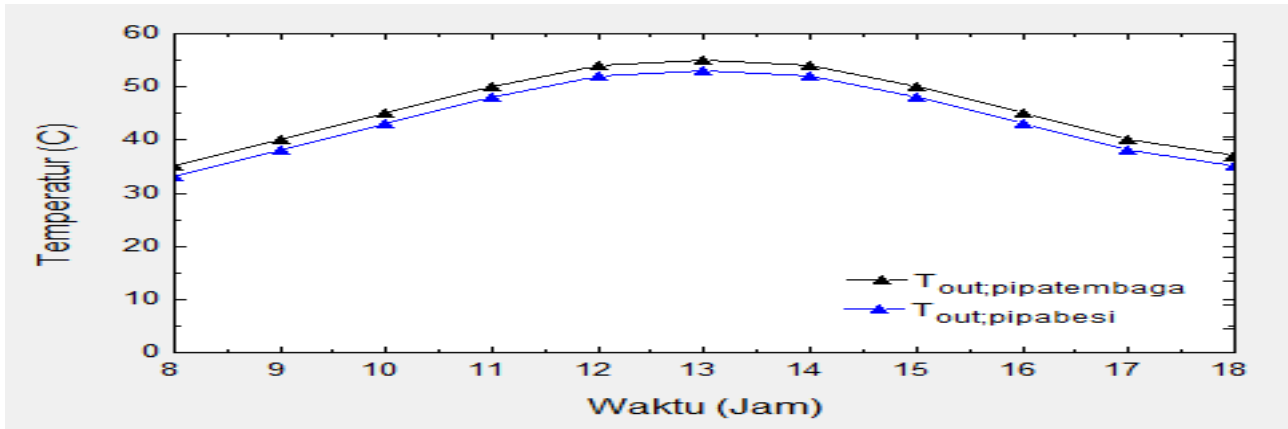

Figure 7. Graph temperatureof out fluid by collector pipe material

The next simulation using aluminum and zinc with a thickness of $0.4 \mathrm{~mm}$ as an absorber, then compared with the test results on 17 July 2012 by using aluminum as an absorber. Comparison of exit temperature of simulation result and test result as in Fig 8.

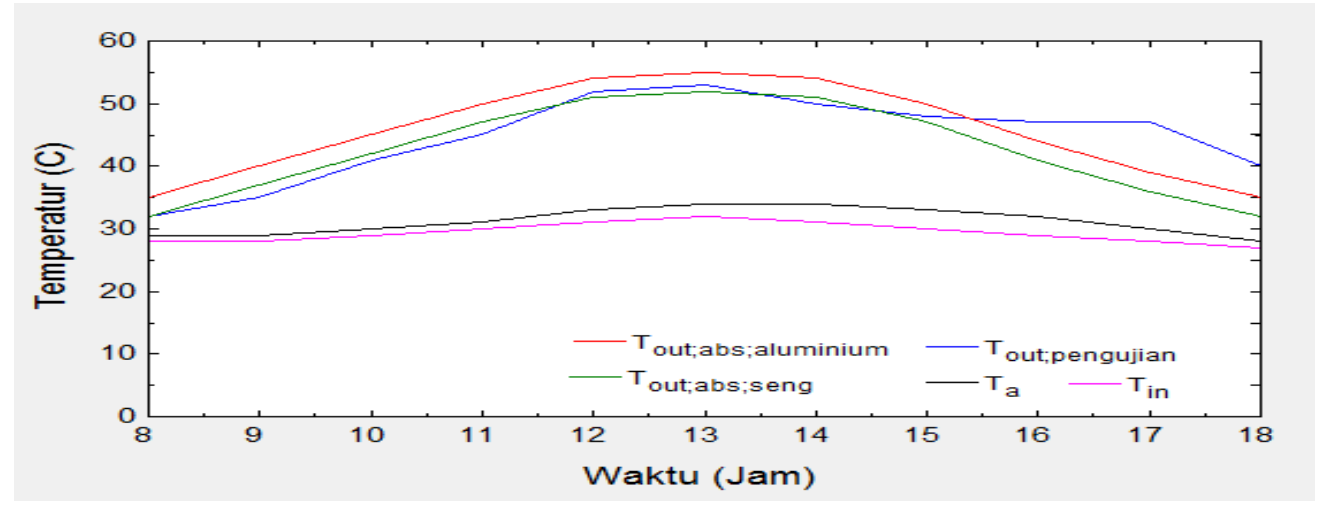

Figure 8. Graph fluid temperature from simulated and test 


\section{Conclusions}

These modeling and simulation are carried out with the main objective of obtaining a reference for the calculation of heat transfer and the absorber material used in flat plate solar collectors. The simulation results were then compared with the results of tests conducted among the Department of Mechanical Engineering Department, Malikussaleh Univerisity. To achieve the goal is modeling by entering the equations and then simulating with the software. From the results of this simulation can be concluded.

\section{References}

[1] Duffie, J. A., Beckman, W. A., 2006, SolarEngineering of Thermal Processes. 3rdedition, Wiley \& Sons.

[2] Migasiuk-WójcickaDorota,ChochowskiAndrzej.,2000, Simulation Model for Solar Water Heating for Food Processing.Journal of Scientific Research and Development. Vol. II. Warsaw, Poland.

[3] G. Faninger, 2012."Solar Hot Water Heating Systems" Comprehensive Renewable Energy", Vol. 3: Solar Thermal Systems: Components and Applications, pp. 419-447,

[4] N. V. Ogueke, E.E. Anyanwu, and O. V. Ekechukwu, 2009. A review of solar water heating systems, journal of renewable energy and sustainable energy, 1, 043106.

[6] Zima W, Dziewa P., 2011, Modelling of liquid flat-plate solar collector operation in transient states, Sage, Poland

[7] Matuska, T., 2003, Transparent thermal insulations and their use in solarenergy applications, Ph.D. thesis, CTU in Prague.

[8] C.cristofari, G. Notto,„P, Poggi, 2002. “ Modelling and Performance of a copolymer Solar Water Heating Collector " Solar Energy. Vol 72, N2.pp.99-112.

[9] A.Zerrouki,A.Boumedien, K.Bouhadef " The Natural Circulation Solar Water Heater with Linear Temperature Distribustion'" Renewable Energy, Vol 26, 2002, pp 549-559.

[10] M.S. Hossain et al.2011, "Review On Solar Water Heater Collector And Thermal Energy Performance Of Circulating Pipe", Renewable Energy And Sustainable Energy Reviews, vol. 15, Issue 8,pp. 3801-3812,

[11] Hottel, H. C., Woertz, B. B., 1942, The performance of flat plate solar heatcollectors.Transactions of ASME, 64, 91-104.

[12] Ropiudin., 2007, Model Thermal Systemand Simulation on solar Oven Surya, IPB, Bogor. 